\title{
Elevated concentrations of 13,14-dihydro-15-keto-prostaglandin F-2 $\alpha$ in maternal plasma during prepartum luteolysis and parturition in dogs (Canis familiaris)*
}

\author{
P. W. Concannon, L. Isaman, D. A. Frank, F. J. Michel and W. B. Currie \\ Department of Physiology, New York State College of Veterinary Medicine, and \\ Department of Animal Science, Cornell University, Ithaca, NY 14853, U.S.A.
}

\begin{abstract}
Summary. Concentrations of progesterone and of 13,14-dihydro-15-keto-prostaglandin F-2 $\alpha$ (PGFM) were measured in plasma collected from 6 bitches every $3 \mathrm{~h}$ starting $2 \cdot 8-4.6$ days before parturition (birth of first pup) and continuing until $0 \cdot 4-0 \cdot 8$ days post partum, and in additional samples collected less frequently. Progesterone concentrations at 48,24, 12 and $3 \mathrm{~h}$ pre partum averaged $2.8 \pm 0.3,2 \cdot 2 \pm 0.4,1.0 \pm 0.3$ and $0.7 \pm 0.2 \mathrm{ng} / \mathrm{ml}$. At those times PGFM values averaged $380 \pm 80,800 \pm 220$, $1450 \pm 450$ and $1930 \pm 580 \mathrm{pg} / \mathrm{ml}$, respectively. Mean concentrations of PGFM increased about $2 \cdot 5$-fold between 48 and $15 \mathrm{~h}$ pre partum in association with the onset of luteolysis, and then increased another 2.5 times before parturition as progesterone fell to nadir values. Peak levels of PGFM ranged from 1060 to $7150 \mathrm{pg} / \mathrm{ml}$ $(2100 \pm 600 \mathrm{pg} / \mathrm{ml})$ and occurred within $1-9 \mathrm{~h}$ after the birth of the first pup and before the birth of the last pup. These results suggest that prepartum luteolysis in dogs is initiated by increases in maternal concentrations of PGF, and that progesterone withdrawal causes a further increase in PGF which completes luteolysis and provides a major portion of the uterotonic activity causing expulsion of pups.
\end{abstract}

Keywords: pregnancy; parturition; luteolysis; prostaglandin; dog

\section{Introduction}

In dogs pregnancy maintenance depends on a luteal source of progesterone throughout gestation and an abrupt decline in progesterone occurs during the $24 \mathrm{~h}$ before parturition (Concannon, $1986 \mathrm{a}, \mathrm{b})$. The prepartum luteolysis has been presumed to be the result of an increase in prostaglandin (PG) F-2 $\alpha$ since exogenous PGF is luteolytic in dogs (Concannon \& Hansel, 1977). However, peripartum changes in peripheral levels of PGF or of its major metabolite, 13,14-dihydro-15-keto-PGF (PGFM) have not been reported for dogs.

The uterotonic and/or luteolytic effect of PGF released by the placenta or uterus has been implicated in the process of parturition in all species in which peripartum changes in PGF or its major metabolite PGFM have been measured (Thorburn \& Challis, 1979; First \& Lohse, 1984). A prepartum increase in PGF occurs in man and other primates in the absence of a withdrawal of progesterone (Liggins et al., 1977; Thorburn \& Challis, 1979; Fuchs \& Fuchs, 1984). It also occurs in sheep, in association with a prepartum decline in progesterone of placental origin, and apparently as a result of a rise in the oestrogen to progesterone ratio effected by an increase in fetal cortisol secretion at term (Thorburn et al., 1977). An increase in PGF has also been reported for

\footnotetext{
*Reprint requests to Dr P. W. Concannon.
} 
several species in which progesterone in late pregnancy is of luteal origin and in which a prepartum luteolysis is either initiated or completed by PGF. These include the goat and cow in which a cortisol-induced rise in maternal oestrogen from the placenta elevates PGF to concentrations that are luteolytic (First \& Lohse, 1984; Currie et al., 1988). In pigs, prepartum luteolysis is also caused by an increase in PGF, but the involvement of a cortisol-induced rise in oestrogen in stimulating the prepartum release of PGF remains uncertain (Coggins et al., 1977; Taverne et al., 1982; First \& Lohse, 1984). The luteolytic prepartum increase in PGF in rabbits has not been correlated with specific changes in peripheral glucocorticoid or oestrogen concentrations (Thorburn \& Challis, 1979). In rats, prepartum luteolysis may precede and thereby cause the rise in PGF, and may be initiated by withdrawal of placental-dependent luteotrophic support (Thorburn \& Challis, 1979; Fuchs \& Fuchs, 1984).

In the pregnant dog, luteal progesterone production is dependent on pituitary gonadotrophins, there is no evidence of a placental luteotrophin or lactogen, a prepartum rise in cortisol but not oestrogen has been reported, and prolactin concentrations increase during prepartum luteolysis (Concannon, 1986a). It was therefore of interest to study peripartum changes in PGF secretion, as reflected in maternal PGFM values, in dogs as they represent a species and order heretofore unstudied in that regard.

\section{Materials and Methods}

Animals. Adult Beagle bitches were routinely maintained in individual indoor runs, exposed to incandescent light $(12 \mathrm{~h}$ light: $12 \mathrm{~h}$ dark; lights on at 07:00 h), provided with food and water ad libitum, and monitored for reproductive characteristics as previously described for this colony (Concannon et al., 1983, 1987). Each of the 6 bitches was mated 3 times during oestrus, and confirmed pregnant by palpation 20-30 days later. The day of the preovulatory LH peak, Day 0 , was determined by radioimmunoassay of $\mathrm{LH}$ in serum samples collected daily during pro-oestrus and oestrus $(\mathrm{N}=3)$ or was estimated to be 8 days before rapid decreases in the extent of the cornified appearance of the vaginal mucosa and vaginal smear (Concannon \& DiGregorio, 1986; Lindsay \& Concannon, 1986). At 7-10 days before the expected Day 65 parturition (Concannon et al., 1983) each bitch was moved to a quiet room with constant illumination, housed in an individual stainless-steel cage containing a plywood nesting box, and provided with sheets of cardboard as nesting material. At 3-5 days before expected parturition, each bitch was fitted with an indwelling 18-gauge jugular catheter (Abbocath, Abbot Hospitals, Chicago) held in place with elastic adhesive tape.

After 0.5-2 days of infrequent blood collection, and starting 2.8-4.6 days before parturition (the birth of the first pup), 3.0-ml blood samples were collected into heparinized syringes every $3 \mathrm{~h}$ until $9-18 \mathrm{~h}$ after the birth of the first pup and then, in 3 bitches, less frequently for 1-2 days. Each sample was immediately transferred to pre-chilled glass tubes in crushed ice, and maintained cold until centrifuged at $800 \mathrm{~g}$ for $20 \mathrm{~min}$ within $1 \mathrm{~h}$ of collection. Aliquants of plasma were transferred to 3-ml polystyrene tubes and stored frozen at $-20^{\circ} \mathrm{C}$ until assay of progesterone or PGFM content. Shortly before each blood collection the bitches were observed for any behavioural or physical signs of impending parturition. However, bitches were not disturbed except for the minimum manipulation required to obtain the blood sample. The haematocrit, as packed cell volume percentage, was determined for samples collected during oestrus and again on the day of, or after, parturition.

Assays. The progesterone assay was as previously described in detail by Fitzgerald \& Butler (1982) using an antiserum for which the only significant cross-reactivity was $11.6 \%$ exhibited by $5 \beta$-dihydroprogesterone. In brief, progesterone was extracted from duplicate plasma samples $(100 \mu \mathrm{l})$ by mechanically shaking each with $3 \mathrm{ml}$ petroleum ether (BP 40-60) and separating the phases by freezing and decanting. Standards were taken from ethanolic stocks. Quality control was routinely monitored by including in each assay aliquants of pools constructed from known amounts of radioinert progesterone (Sigma Chemical Company, St Louis, MO) added to bulk volumes of goat plasma that had been treated previously with charcoal, dog plasma with elevated concentrations of progesterone and plasma from ovariectomized dogs. Overall recoveries of added progesterone were consistently between 91 and $94 \%$. Values were not adjusted for procedural losses. All samples from each bitch were included in a single assay. The coefficients of variation within and between assays were 9 and $15 \%$, respectively.

PGFM analysis was as previously described in detail (Currie et al., 1988), and involved sample preparation methods reported by Cooke \& Homeida (1982) and radioimmunoassay procedures described by Olson \& Hertelendy (1981). Each sample was assayed in duplicate. Quality control measures included the assay of water and diethyl ether blanks and the routine inclusion of aliquants of pools constructed from charcoal-treated goat plasma containing known additions of radioinert PGFM, and dog plasma with high and low endogenous concentrations of prostaglandin. Recoveries varied between 83 and $87 \%$. A concentration of $39 \mathrm{pg} / \mathrm{ml}$ was reliably distinguished from zero. All samples from each bitch were analysed in a single assay. No correction was applied for procedural losses. The coefficients of variation within and between assays averaged $10-15 \%$ and $12 \%$, respectively. 
For data presentation and calculation of means all values were aligned to a common Day 65 parturition based on the sample taken during delivery of the first pup or immediately thereafter. Values are reported as mean \pm s.e.m.

\section{Results}

All parturitions occurred 64-66 days after the actual or estimated day of the preovulatory LH peak. Litter size ranged from 5 to 10 pups, and averaged $7 \cdot 8 \pm 0.7$. The intervals between births of first and last pups ranged from 7 to $21 \mathrm{~h}$ and averaged $12.2 \pm 1.9 \mathrm{~h}$. Haematocrits at the time of parturition ranged from 26 to $34 \%$ and averaged $29 \cdot 0 \pm 1 \cdot 2 \%$. Those at oestrus ranged from 41 to $49 \%$ and averaged $44.6 \pm 1.2 \%$.

Intermittent observations at $0 \cdot 5-3 \cdot 0 \mathrm{~h}$ intervals before the birth of the first pup indicated that each of the bitches remained quiet and/or did not show any consistent protracted changes in behaviour. More frequent or continuous observations between the births of the 1st and 4th pups indicated the consistent occurrence of several behaviours. These included intense pawing, digging and scratching at the floor of the nesting box, panting, whining, abdominal straining and licking the vulva and perineum.

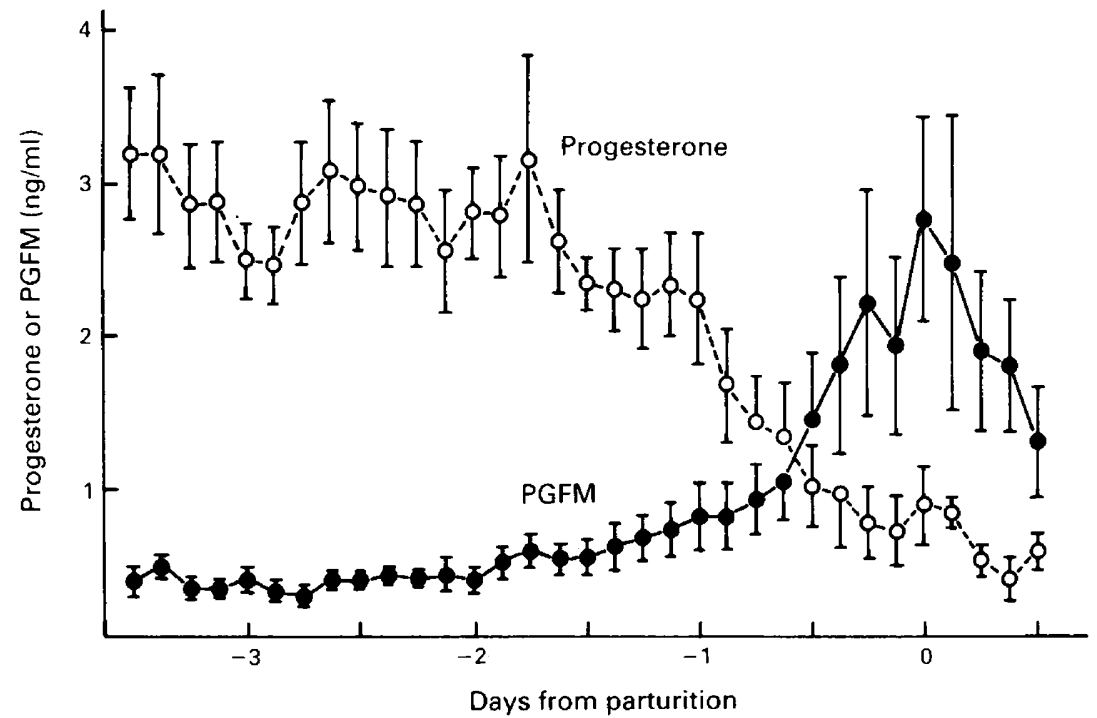

Fig. 1. Mean ( \pm s.e.m.) concentrations of progesterone and of 13,14-dihydro-15-ketoprostaglandin F-2 $\alpha$ (PGFM) in the plasma of 6 pregnant bitches around the time of parturition. All values were aligned to a common Day 65 of parturition based on the sample obtained at or immediately after the birth of the first pup, which occurred in individual bitches at 64-66 days after the day of the preovulatory LH surge.

Mean concentrations of progesterone and PGFM in plasma around the time of parturition are provided in Fig. 1. Those for two individual bitches are in Fig. 2. There was an abrupt decline in progesterone concentrations during the $24 \mathrm{~h}$ before parturition. Progesterone values at 3 days before parturition ranged from $2 \cdot 3$ to $4.5 \mathrm{ng} / \mathrm{ml}$ and averaged $3.3 \pm 0.3 \mathrm{ng} / \mathrm{ml}$. By $12 \mathrm{~h}$ before parturition progesterone concentrations were reduced to $0.3-2.2 \mathrm{ng} / \mathrm{ml}$ and averaged $1.2 \pm 0.2 \mathrm{ng} / \mathrm{ml}$. At $1-3 \mathrm{~h}$ before the onset of parturition progesterone was $0.2-1.7 \mathrm{ng} / \mathrm{ml}$ and averaged $0.7 \pm 0.2 \mathrm{ng} / \mathrm{ml}$. Concentrations of PGFM in plasma at 3 days before parturition ranged from 280 to $590 \mathrm{pg} / \mathrm{ml}$ and averaged $390 \pm 50 \mathrm{pg} / \mathrm{ml}$. Starting at approximately 21-39 $(29 \pm 3) \mathrm{h}$ 
before parturition, PGFM concentrations in individual bitches (Fig. 2) became consistently elevated above preceding values. PGFM then progressively increased, reaching 570-2805 $(1190 \pm 320) \mathrm{pg} / \mathrm{ml}$ at $12 \mathrm{~h}$ pre partum, followed by levels of $900-4210(2100 \pm 600) \mathrm{pg} / \mathrm{ml}$ at $1-3 \mathrm{~h}$ pre partum, and higher levels post partum. Before parturition PGFM reached levels as high as $900-4970(2525 \pm 750) \mathrm{pg} / \mathrm{ml}$ at $1-12 \mathrm{~h}(5 \pm 2 \mathrm{~h})$ before the birth of the first pup. PGFM continued to increase and reached peak levels of $1060-7150(3640 \pm 815) \mathrm{pg} / \mathrm{ml}$ at $0-9 \mathrm{~h}$ after the birth of the first pup and before the birth of the last pup of the litter, after which values declined. There was no obvious relation between litter size and PGFM concentrations.

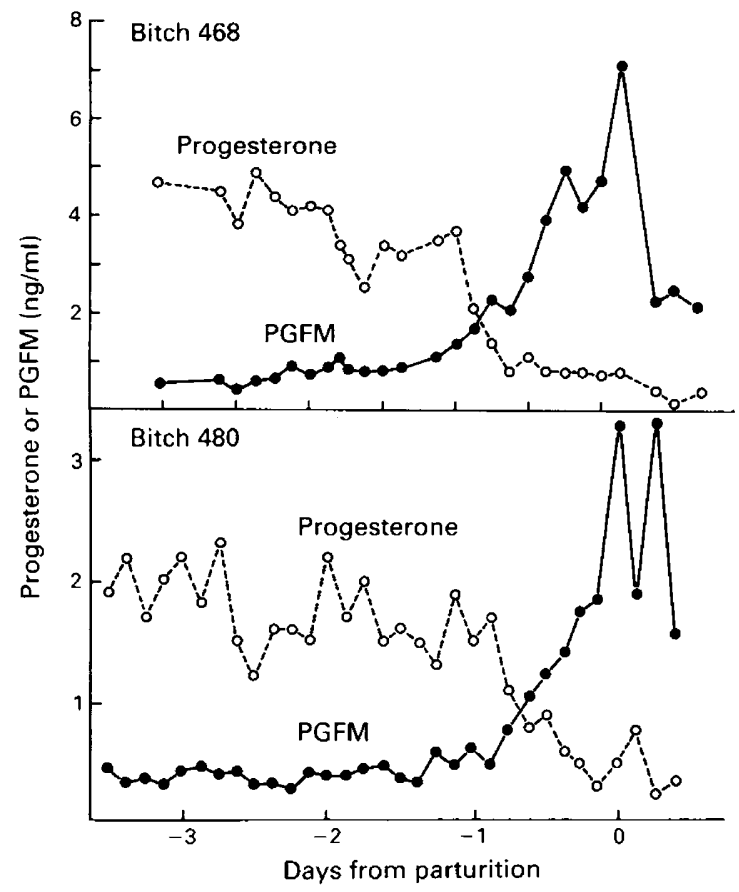

Fig. 2. Concentrations of progesterone and of 13,14-dihydro-15-keto-prostaglandin F-2 $\alpha$ (PGFM) in 2 pregnant bitches around the time of parturition. Values in both animals have been aligned to a common Day 65 of parturition (birth of the first pup).

\section{Discussion}

The present results confirm for dogs a low variation in the time of parturition relative to the $\mathrm{LH}$ peak (Concannon et al., 1983; Concannon \& Castracane, 1985), an abrupt prepartum decline in progesterone (Concannon et al., 1977, 1978) and a marked reduction in haematocrit over the course of pregnancy (Andersen \& Schalm, 1970; Concannon et al., 1977). The prepartum decline in progesterone is required for normal parturition in dogs and its prevention by administration of exogenous progesterone blocked parturition and resulted in deaths of pups in situ (Concannon et al., 1977). The decline in progesterone probably reflects lysis of corpora lutea, although alterations in progesterone metabolism could also be involved. Corpora lutea are the major if not only source of progesterone during canine pregnancy. Ovariectomy at any time during pregnancy results in abortion or resorption (Sokolowski, 1974). Progesterone concentrations declined rapidly to very low levels after ovariectomy of bitches in which pregnancy was maintained by a synthetic progestagen (Concannon et al., 1977). Termination of luteal progesterone secretion by 
bromocriptine-induced hypoprolactinemia causes a decline in progesterone concentrations to less than $1 \mathrm{ng} / \mathrm{ml}$ and results in abortion during the second half of gestation (Concannon et al., 1987). Histochemical studies of the dog placenta suggest that there is little if any de-novo placental steroidogenesis (Kiso \& Yamouchi, 1984).

The prepartum increases in maternal concentrations of PGFM suggest that corresponding increases in peripheral values of PGF, due to its uterotonic effect in the bitch (Wheaton et al., 1986), plays a major role in parturition in dogs as in other species. Measurements of PGFM reflect PGF secretion into the circulation more accurately than do those of the primary prostaglandin itself (Samuelsson et al., 1978). Basal concentrations of PGFM observed in this study were comparable to those previously reported for late pregnancy in the dog (Gerber et al., 1979). The peripartum peak values of PGFM in dogs were comparable to those reported for sheep (Mitchell et al., 1976) and goats (Currie et al., 1988) and lower than those in pigs (Nara \& First, 1981). That the increases in PGFM occur concomitant with the decline in progesterone suggests that PGF initiates the prepartum luteolysis observed in this species, since PGF is luteolytic in dogs (Concannon \& Hansel, 1977; Paradis et al., 1983). Placental and/or uterine release of luteolytic amounts of prostaglandin has been suggested to play a role in the initiation, or completion of prepartum luteolysis in other species in which corpora lutea are the main source of progesterone throughout gestation. The latter include the goat (Currie et al., 1988), pig (First \& Lohse, 1984), rabbit (Thorburn \& Challis, 1979), and rat (Fuchs et al., 1976). However, in the rat initiation of luteolysis apparently precedes and probably initiates the prepartum rise in PGFM (Puri \& Garfield, 1982) and may itself be due to withdrawal of placental gonadotrophin or luteotrophic placental lactogen (Thorburn \& Challis, 1979). A similar mechanism in the dog seems unlikely, since there is no evidence for a placental gonadotrophin in dogs, the dog placenta does not possess placental lactogen activity (Shiu et al., 1973; Talamantes, 1975; Forsyth, 1986), and maternal prolactin concentrations are elevated during prepartum luteolysis (Concannon et al., 1978; DeCoster et al., 1983).

The mechanism of prepartum luteolysis and parturition in dogs may be initiated by increased fetal secretion of adrenocorticosteroids as proposed for several other species (Thorburn et al., 1977; Nathanielsz, 1978; Thorburn \& Challis, 1979; Liggins et al., 1977). In earlier studies of parturition in dogs, maternal cortisol concentrations fluctuated within a normal range of $15-25 \mathrm{ng} / \mathrm{ml} \mathrm{during}$ the last week of gestation, were elevated to $40-80 \mathrm{ng} / \mathrm{ml}$ during luteolysis 1 day pre partum in most bitches, and were then reduced to $10-25 \mathrm{ng} / \mathrm{ml}$ during or immediately after parturition (Concannon et al., 1977, 1978). The increase in maternal cortisol concentrations may represent a far greater increase in fetal cortisol secretion, and the latter could act to promote the release of luteolytic amounts of PGF. Administration of exogenous glucocorticoid was reported to terminate pregnancy in dogs (Austad et al., 1976) but the ability of glucocorticoids to increase PGF or PGFM concentrations in late pregnant dogs has not been studied. Measurements of fetal cortisol values around the time of parturition in dogs have not been reported.

The protracted rise in PGF during and after luteolysis and throughout delivery probably involves mechanisms other than those initiated by cortisol. In several species uterine production and release of PGF are stimulated by progesterone withdrawal (Nathanielsz, 1978; Thorburn \& Challis, 1979; Puri \& Garfield, 1982) and by oxytocin (Mitchell et al., 1975; Fuchs \& Fuchs, 1984). Similarly, in dogs, it is probable that the prepartum fall in progesterone promotes a self-sustaining luteolytic rise in PGF, and that oxytocin stimulates release of PGF throughout labour.

While increases in cortisol may initiate increased release of PGF in the dog, the effect may not be mediated by an increase in placental oestrogen production as suggested for cattle, sheep, and goats (First \& Lohse, 1984). In dogs, as in pigs, there is no evidence for a distinct prepartum rise in total oestrogen (Concannon et al., 1977), oestradiol or oestrone (Chakraborty, 1987) concentrations. Likewise, there is no rise in androgens which might serve as oestrogen precursors. Androgen concentrations parallel those of progesterone (Concannon \& Castracane, 1985). However, prepartum changes in placental or uterine oestrogen values or in maternal plasma concentrations of oestrogen conjugates have not been reported for dogs. 
We thank S. Anderson, C. Doherty, and A. Montanez for technical assistance; and Mr G. Grossmann and R. McGuire for animal care. This research was supported, in part, by grants from the Morris Animal Foundation and the New York State College of Veterinary Medicine Alumni Fund.

\section{References}

Andersen, A.C. \& Schalm, O.O. (1970) Hematology. In The Beagle as an Experimental Animal, Chap. $11 \mathrm{c}$, pp. 261-281. Ed. A. C. Andersen. Iowa State University Press, Ames, Iowa.

Austad, R., Lunde, A. \& Sjaastad, O.V. (1976) Peripheral plasma levels of oestradiol-17 $\beta$ and progesterone in the bitch during the oestrous cycle, in normal pregnancy and after dexamethasone treatment. $J$. Reprod. Fert. 46, 129-36.

Chakraborty, P. (1987) Reproductive hormone concentrations during estrus, pregnancy and pseudopregnancy in the Labrador bitch. Theriogenology 27, 827-840.

Coggins, E.G., Van Horn, D. \& First, N.L. (1977) Influence of prostaglandin $\mathrm{F}$, dexamethasone, progesterone and induced corpora lutea on porcine parturition. J. Anim. Sci. 45, 754-762.

Concannon, P.W. (1986a) Canine pregnancy and parturition. Vet. Clin. N. Amer. 16, 453-475.

Concannon, P.W. (1986b) Clinical and endocrine correlates of canine ovarian cycles and pregnancy. In Current Veterinary Therapy, Small Animal Practice, Vol. VIII, pp. 1214-1224. Ed. R. Kirk. W. B. Saunders, Philadelphia.

Concannon, P.W. \& Castracane, V.D. (1985) Serum androstenedione and testosterone concentrations during pregnancy and nonpregnant cycles in dogs. Biol. Reprod. 33, 1078-1083.

Concannon, P.W. \& DiGregorio, G.B. (1986) Canine vaginal cytology. In Small Animal Reproduction and Infertility, pp. 96-111. Ed. T. Burke. Lea and Febiger, Philadelphia.

Concannon, P.W. \& Hansel, W. (1977) Prostaglandin $\mathbf{F}_{2 a}$-induced luteolysis, hypothermia and abortions in Beagle bitches. Prostaglandins 13, 533-542.

Concannon, P.W., Powers, M.E., Holder, W. \& Hansel, W. (1977) Pregnancy and parturition in the bitch. Biol. Reprod. 16, 517-526.

Concannon, P.W., Butler, W.R., Hansel, W., Knight, P.J. \& Hamilton, J.M. (1978) Parturition and lactation in the bitch: serum progesterone, cortisol and prolactin. Biol. Reprod. 19, 1113-1118.

Concannon, P.W., Whaley, S., Lein, D. \& Wissler, R. (1983) Canine gestation length: variation related to time of mating and fertile life of sperm. Am. J, vet. Res. 44, $1819-1821$.

Concannon, P.W., Weinstein, R., Whaley, S. \& Frank, D. (1987) Suppression of luteal function in dogs by luteinizing hormone antiserum and by bromocriptine. $J$. Reprod. Fert. 81, 175-180.

Cooke, R.G. \& Homeida, A.B. (1982) Plasma concentrations of 13,14-dihydro-15-keto-prostaglandin $F_{2 a}$ and progesterone during oxytocin-induced oestrus in the goat. Theriogenology 18, 453-460.
Currie, W.B., Gorewit, R.C. \& Michel, F.J. (1988) Endocrine changes, with special emphasis on oestradiol-17 $\beta$, prolactin and oxytocin, before and during labour and delivery in goats. $J$. Reprod. Fert. 82, 299-308.

DeCoster, R., Beckers, J.F., Beerens, D. \& DeMay, J. (1983) A homologous radioimmunoassay for canine prolactin: plasma levels during the reproductive cycle. Acta endocr., Copenh. 103, 473-478.

First, N.L. \& Lohse, T.K. (1984) Mechanisms initiating parturition. Proc. I0th Int. Congr. Anim. Reprod. \& A.I.., Champaign-Urbana, vol. V, 31-42.

Fitzgerald, J. \& Butler, W.R. (1982) Seasonal effects and hormonal patterns related to puberty in ewe lambs. Biol. Reprod. 27, 853-863.

Forsyth, I.A. (1986) Variation among species in the endocrine control of mammary growth and function: the roles of prolactin, growth hormones, and placental lactogen. J. Dairy Sci. 69, 886-903.

Fuchs, A.R. \& Fuchs, F. (1984) Endocrinology of human parturition: A review. Br.J. Obstet. Gynaecol. 91, 948-967.

Fuchs, A.R., Smitasiri, Y. \& Chantharasksri, U. (1976) The effect of indomethacin on uterine contractility and luteal regression in pregnant rats at term. $J$. Reprod. Fert. 48, 331-340.

Gerber, J., Hubbard, W. \& Nies, A. (1979) Uterine vein prostaglandin levels in late pregnant dogs. Prostaglandins 17, 623-637.

Kiso, Y. \& Yamauchi, S. (1984) Histochemical study on hydroxysteroid dehydrogenases in the trophoblast of the dog placenta. Jpn. J. vet. Sci. 46, 219-223.

Liggins, G.C., Forster, C., Grieves, S. \& Schwartz, A. (1977) Control of parturition in man. Biol. Reprod. 16, 39-56.

Lindsay, F.E.F. \& Concannon, P.W. (1986) Normal canine vaginoscopy. In Small Animal Reproduction and Infertility, pp. 112-120. Ed. T. Burke. Lea and Febiger, Philadelphia.

Mitchell, M.D., Flint, A.P.F. \& Turnbull, A.C. (1975) Stimulation by oxytocin of prostaglandin $F$ levels in uterine venous effluent in pregnant and puerperal sheep. Prostaglandins 9, 47-56.

Mitchell, M.D., Flint, A.P.F. \& Turnbull, A.C. (1976) Plasma concentrations of 13,14-dihydro-15-ketoprostaglandin $F$ during pregnancy in sheep. Prostaglandins 11, 319-329.

Nara, B.S. \& First, N.L. (1981) Effect of indomethacin and prostaglandin $\mathrm{F}_{2 a}$ on parturition in swine. $J$. Anim. Sci. 53, 1360-1370.

Nathanielsz, P.W. (1978) Endocrine mechanisms of parturition. Ann. Rev. Physiol. 40, 411-445.

Olson, D.M. \& Hertelendy, F. (1981) Plasma levels of 13,14-dihydro-15-keto-prostaglandin $F_{2 \alpha}$ in relation 
to oviposition and ovulation in the domestic hen (Gallus domesticus). Biol. Reprod. 24, 496-504.

Paradis, M., Post, K. \& Mapletoft, R. (1983) Effects of prostaglandin $\mathrm{F}_{2 \alpha}$ on corpora lutea formation and function in mated bitches. Canad. vet. J. 24, 239-242.

Puri, C.P. \& Garfield, R.E. (1982) Changes in hormone levels and gap junctions in the rat uterus during pregnancy and parturition. Biol. Reprod. 27, 967-975.

Samuelsson, B., Goldyne, M., Grandstrom, E., Hamberg, M., Hammarstrom, S. \& Malmsten, C. (1978) Prostaglandins and thromboxanes. Ann. Rev. Biochem. 47, 997-1029.

Shiu, R.P.C., Kelly, P.A. \& Friesen, H.G. (1973) Radioreceptor assay for prolactin and other lactogenic hormones. Science, N.Y. 180, 968-971.

Sokolowski, J. (1974) The effects of ovariectomy on pregnancy maintenance in the bitch. Lab. Anim. Sci. 21, 696-699.
Talamantes, F. (1975) Comparative study of the occurrence of placental prolactin among mammals. Gen. comp. Endocrinol. 27, 115-121.

Taverne, M., Bevers, M., Bradshaw, J., Dielman, S.J., Willemse, A.H. \& Porter, D.G. (1982) Plasma concentrations of prolactin, progesterone, relaxin and oestradiol-17 $\beta$ in sows treated with progesterone, bromocriptine or indomethacin during late pregnancy. J. Reprod. Fert. 65, $85-96$.

Thorburn, G.D. \& Challis, J.R.G. (1979) Endocrine control of parturition. Physiol. Rev. 59, 863-916.

Thorburn, G.D., Challis, J.R. \& Currie, W.B. (1977) Control of parturition in domestic animals. Biol. Reprod. 16, 18-27.

Wheaton, L., Rodriguez-Martinez, H., Weston, P., Ko, C.-H. \& Gustafsson, B. (1986) Recording uterine motility in the nonanesthetized bitch. Am.J. vet. Res. 47, 2205-2207.

Received 10 November 1987 